\title{
Article \\ Numerical Optimization for the Impact Performance of a Rubber Ring Buffer of a Train Coupler
}

\author{
Ping $X u^{1,2,3,4}$, Chengju $Q u^{1,2,3}$, Shuguang Yao ${ }^{1,2,3}$, Chengxing Yang $1,2,3, * \mathbb{C}$ and Ao Wang $1,2,3$ \\ 1 Key Laboratory of Traffic Safety on Track, Ministry of Education, School of Traffic \& Transportation \\ Engineering, Central South University, Changsha 410075, China; xuping@csu.edu.cn (P.X.); \\ Chengju_Qu_Hn@163.com (C.Q.); ysgxzx@csu.edu.cn (S.Y.); csu_wang_ao@csu.edu.cn (A.W.) \\ 2 Joint International Research Laboratory of Key Technology for Rail Traffic Safety, Central South University, \\ Changsha 410075, China \\ 3 National \& Local Joint Engineering Research Center of Safety Technology for Rail Vehicle, \\ Central South University, Changsha 410075, China \\ 4 State Key Laboratory of High Performance Complex Manufacturing, Central South University, \\ Changsha 410075, China \\ * Correspondence: Chengxing_Yang_Hn@163.com
}

Citation: Xu, P.; Qu, C.; Yao, S.; Yang, C.; Wang, A. Numerical Optimization for the Impact

Performance of a Rubber Ring Buffer of a Train Coupler. Machines 2021, 9 , 225. https://doi.org/10.3390/ machines 9100225

Academic Editor: César M. A. Vasques

Received: 30 August 2021

Accepted: 30 September 2021

Published: 2 October 2021

Publisher's Note: MDPI stays neutral with regard to jurisdictional claims in published maps and institutional affiliations.

Copyright: (c) 2021 by the authors. Licensee MDPI, Basel, Switzerland. This article is an open access article distributed under the terms and conditions of the Creative Commons Attribution (CC BY) license (https:/ / creativecommons.org/licenses/by/ $4.0 /)$.

\begin{abstract}
Shock and vibration caused by mechanical motion bring huge potential threats to the service life and assembly reliability of mechanical systems. Rubber materials have been widely used in aircraft, trains, and other engineering fields, due to their excellent properties in shock and vibration absorption. This paper aimed to study the rubber ring buffer applied to a certain type of Chinese locomotive. Firstly, the finite element model was established and verified through experimental data. Based on the verified simulation model, the influence of the constitutive parameters $\left(C_{01} / C_{10}\right.$ ratio height $H$ and contour radius $R$ ) of the rubber ring on its energy absorption and peak crushing force under impact loading was studied in a numerical environment. Finally, the design of the experiment was carried out by the optimized Latin hypercube method, and the response surface model was established, which intuitively demonstrated the influence of the relevant parameters of the rubber ring on the change trend of the energy absorption and peak force. Based on the proxy model, the parameters that improve the crashworthiness of the rubber ring buffer were found quickly by the NSGA-II optimization algorithm, and the problems of a long calculation time and low optimization efficiency when using the conventional finite element method were avoided. The optimization results stated that when $H=107.57 \mathrm{~mm}$ and $R=85.70 \mathrm{~mm}, C_{01} / C_{10}=0.0571$ of the energy absorption of the optimized buffer was increased by $59.03 \%$, and the peak force was decreased by $14.37 \%$, compared with the original structure. The optimized rubber ring buffer is expected to reduce the peak crushing force, enhance the energy absorption capacity, and mitigate the damage to the train system caused by shock and vibration.
\end{abstract}

Keywords: rubber ring buffer; Mooney-Rivilin model; parametric study; multi-objective optimization

\section{Introduction}

During the operation of a train, there is a coupling relationship between adjacent vehicles in the longitudinal, lateral, and vertical directions. The longitudinal impulse of the train will have a greater impact on the lateral and vertical dynamics of the vehicle, as it is an important factor that affects the comfort and safety of the vehicle. The buffer has the function of dissipating the shock and vibration energy between the vehicles, thereby reducing the damage to the car body structure and the loaded goods, simultaneously improving the running stability of the train. In order to better discover and understand the relevant properties of rubber buffers, the cushioning performance and energy absorption characteristics of rubber materials have become the focus of research in many fields.

Lin et al. [1] established a buffer collision simulation mathematical model based on the test data of a railway buffer system, which overcomes the difficulty of the railway 
vehicle buffer through the actual vehicle collision test and performance evaluation. By studying the cushioning characteristics of a 10-car train colliding at $25 \mathrm{~km} / \mathrm{h}$, it was proved that the buffer can better match the energy dissipation. Wu et al. [2] established a finite element model of the rubber extrusion process by the Euler-Lagrangian coupling method, and simulated the expansion phenomenon in the rubber extrusion process, which was consistent with reality. The extrusion process parameters were optimized by the finite element method, and the tire forming quality was improved. Wang et al. [3] established the finite element model of the steering rubber buffer seat of the loader, and determined the design variables, constraint function, and objective function of the optimal design model of the rubber buffer seat in detail. Through optimization and iterative calculation, the optimal design parameters of the design model of the steering rubber cushion seat of the loader were found finally, which improved the comfort of the machine operation and, recognized by the market, it proves the correctness and rationality of the finite element design method. Zhang et al. [4] used the improved non-linear mathematical model of the buffer and the dynamic model verified by experiments to study the parameters affecting the stability of coupler compression and the safety of locomotive operation. Shang et al. [5] used finite element simulation technology to analyze and predict the static characteristics of rubber components, indicating the effectiveness of the finite element prediction method and indicating that the finite element analysis method can play an important role in the design of rubber vibration isolators. Peng et al. [6] established the finite element simulation model of the FRP rubber bearing, studied the influence of its size parameters on the compression performance, and obtained the influence law of the size parameter, which provided a reference for the engineering design of the FRP rubber bearing. Pang et al. [7] proposed a new finite element method for static calculation and analysis of automobile composite rubber suspension, and conducted stress distribution and deformation analysis on rubber suspension under different working conditions through finite element software. It provides a reference for the virtual design and lightweight design of vehicle composite rubber suspension. Tao et al. [8] proposed an improved superelastic constitutive model, and carried out related finite element simulation calculations based on the test data of filled rubber. The results showed that the constitutive model has the characteristics of accurate results, less material parameters, and simple testing for simulated rubber materials. Freckley et al. [9] deduced the empirical formula of the IRHD (International Rubber Hardness Degrees) hardness $\mathrm{Hr}$ and elastic modulus $\mathrm{E}_{0}$ of rubber materials through related experiments, which laid the foundation for the reverse calculation of rubber material parameters. Zhang et al. [10] derived the constitutive equation of rubber material based on the hyperelasticity theory, and obtained the material parameters by fitting the experiment data. Based on the established simulation method of rubber ring sealing's performance, the excellent sealing performance of the proposed new butterfly rubber ring was verified. Mariusz et al. [11] determined the basic stiffness under a variable strain rate through the compression test results of a rubber bumper, so as to adjust the numerical model of the buffer, and finally obtained an improved rubber buffer and a numerical model that can be used for accurate simulation. Shi et al. [12] used a new type of rubber material strain energy function to analyze the large deformation of an incompressible rubber cylinder under internal pressure, and proposed a new method to control the calculation stability and convergence rate, and the influence of the choice of penalty factor on the result of finite element calculation was also discussed. Yildiz [13] determined the actual performance of the rubber fender through experiments and used three different strain energy functions as the superelastic material model in its finite element analysis. After comparing the results of the experiments and simulations, the most suitable strain energy function hyperelastic material model of the rubber fender was determined finally. Wang et al. [14] analyzed the factors of the stress field and strain field of rubber joints and the relationship between these factors and the location of fatigue cracks through threedimensional finite element simulation. The results showed that the stress concentration is not sensitive to the prediction of a fatigue crack's location, and the method of using strain 
concentration to predict the fatigue crack location of rubber joints was proposed. This method is of great significance to the design of rubber joints and the theoretical study of fatigue strength.

The energy absorption of the rubber buffer mainly relies on its own elastoplastic deformation and friction with related parts. Due to the unique super-elastic properties of rubber, there is a certain difference in energy absorption from metal deformation. These characteristics have also become an attraction for researchers to study [15,16]. Resistancedisplacement is an important indicator of the energy absorption of the buffer, and the area enclosed by the curve is the energy absorption of the buffer. Sometimes, these data will become input data for studying multi-body dynamics [17]. The commonly used methods to obtain the resistance-displacement curve include the static compression test and drop hammer impact test. Li et al. [18] determined the dynamic mechanical properties of highdamping rubber through the Hopkinson pressure bar (SHPB) test. The results showed that the stress-strain curve and dynamic modulus of high-damping rubber have obvious strain rate effects. The strength and energy absorption capacity of the material increase with the increase of the strain rate. Yao et al. [19] studied the quasi-static and impact energy absorption characteristics of railway vehicle rubber buffers by using quasi-static tests and drop-weight tests. Zhang et al. [20] analyzed the energy absorption value of rubber materials under a dynamic impact load. The study found that the strain value effect of rubber is very obvious, and the hardness of rubber is an important factor affecting the energy absorption value. Chen et al. [21] developed a high computational efficiency method to simulate the vertical dynamic behavior of the vehicle-track coupling system, and adopted the direct solution algorithm instead of the iterative method, which significantly improved the overall computational efficiency. Compared with existing models, the accuracy and efficiency of this method have been studied. Cui et al. [22] proposed a model simplification method to analyze the dynamic response of beam structures under moving loads, and successively applied this technique to simply supported beams under single point loads moving along the beam and a practical model for dynamic analysis of wheel-rail interaction in railway engineering. Numerical examples show that the condensation model can solve the moving load problem more quickly than the analytical model or the full finite element model, and the model has higher calculation accuracy. Chen et al. [23] studied the influence of the friction coefficient, wave grinding depth, and wave grinding wavelength on rail wave grinding development. The results show that the vibration caused by wheel-rail friction can cause rail wrinkling, and the uneven feedback vibration of rail wrinkling can aggravate the development of subsequent rail wrinkling.

At present, the research on rubber products mainly adopts the method of combining finite element simulation with experiments, and the general finite element method requires high computing resources and takes a long time. Experimental methods need to consume more human and material resources. If the proxy model is used for research, the efficiency of calculation and optimization will be greatly improved, and the change rule between research parameters and responses can be seen intuitively. In this paper, based on the Mooney-Rivilin constitutive model of rubber compression, the effects of different ratios of constitutive parameter ratios $C_{01} / C_{10}$, rubber ring buffer height $H$, and contour radius $R$ on rubber ring buffer energy absorption and peak force were studied through ABAQUS simulation, and the relationship between each parameter and response was established by building a proxy model. The optimum performance parameters of the rubber ring buffer were obtained.

\section{Finite Element Modeling}

\subsection{Description of the Structure and Position of the Rubber Ring Buffer}

The rubber ring buffer described in this paper is located between the coupler and the body buffer beam, which is used to connect the body buffer beam and the train coupler, and plays a certain role in cushioning energy absorption and shock absorption for the 
longitudinal impact of the train. The specific position is shown in Figure 1a, and the details of the train coupler and rubber buffer are shown in Figure $1 b$.

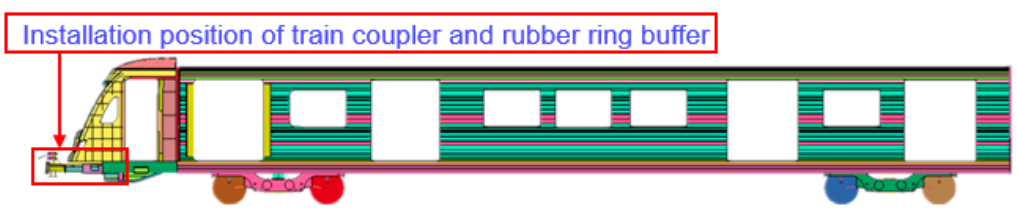

(a)

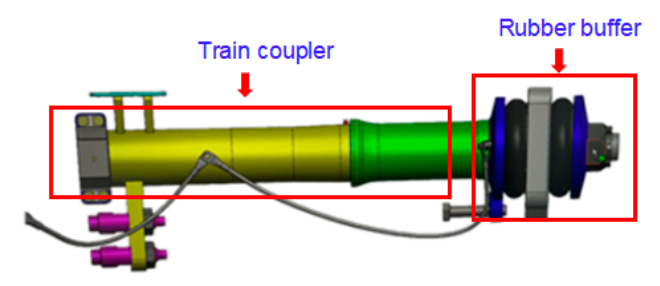

(b)

Figure 1. (a) Installation position diagram of the rubber ring buffer; (b) detailed drawing of the train coupler and rubber buffer.

\subsection{Introduction of the Mooney-Rivilin Model}

The Mooney-Rivilin model is based on the phenomenological theory of large elastic deformation [24], which is based on two assumptions:

1. Rubber is isotropic in the undeformed state and has an incompressibility volume.

2. Hooke's law is followed in the shear deformation, that is, the stress and strain are in a linear relationship. The constitutive relationship of the rubber material can be expressed as a function of the three invariants $\left(I_{1}, I_{2}, I_{3}\right)$ of the deformation tensor by a strain energy density function, or as a function of the three main elongation ratios $\left(\lambda_{1}, \lambda_{2}\right.$, and $\left.\lambda_{3}\right)$ :

$$
\begin{gathered}
I_{1}=\lambda_{1}^{2}+\lambda_{2}^{2}+\lambda_{3}^{2} \\
I_{2}=\lambda_{1}^{2} \lambda_{2}^{2}+\lambda_{2}^{2} \lambda_{3}^{2}+\lambda_{3}^{2} \lambda_{1}^{2} \\
I_{3}=\lambda_{1}^{2} \lambda_{2}^{2} \lambda_{3}^{2}
\end{gathered}
$$

According to the incompressibility volume of rubber materials, the following relationship is introduced:

$$
I_{3}=\lambda_{1}^{2} \lambda_{2}^{2} \lambda_{3}^{2}=1
$$

Substituting formula (4) into formula (2), the following relationship can be obtained:

$$
I_{2}=\lambda_{1}^{-2}+\lambda_{2}^{-2}+\lambda_{3}^{-2}
$$

Regarding $I_{1}$ and $I_{2}$ as two independent variables, which is determined by the three stretching ratios, the strain energy density $(W)$ of an isotropic incompressible material can be expressed as:

$$
W=\sum_{i+j=1}^{N} C_{i j}\left(I_{i}-3\right)^{i} *\left(I_{j}-3\right)^{j}
$$

where $C_{i j}$ is the material constant.

Generally, the Mooney-Rivlin model is widely used, namely:

$$
W=C_{10}\left(I_{1}-3\right)+C_{01}\left(I_{2}-3\right)
$$

This model can describe the characteristics of rubber deformation within the elongation of $150 \%$ well [25]. 
From the relationship between the Kirchoff stress tensor and Green strain tensor, the relationship between the principal stress $\sigma_{\mathrm{i}}$ of the rubber material and its principal elongation ratio $\lambda_{\mathrm{i}}$ is:

$$
\sigma_{\mathrm{i}}=2\left(\lambda_{i}^{2} \frac{\partial w}{\partial I_{1}}+\frac{1}{\lambda_{i}^{2}} \frac{\partial w}{\partial I_{2}}\right)+P
$$

where $P$ is the unknown pressure reflecting that the rubber is incompressible and insensitive to the pressure [26].

From formula (8), the differences among three principal stresses (engineering stress) can be obtained as:

$$
\begin{aligned}
& \sigma_{1}-\sigma_{2}=2\left(\lambda_{1}^{2}-\lambda_{1}^{2}\right)\left(\frac{\partial w}{\partial I_{1}}+\lambda_{3}^{2} \frac{\partial w}{\partial I_{2}}\right) \\
& \sigma_{2}-\sigma_{3}=2\left(\lambda_{2}^{2}-\lambda_{3}^{2}\right)\left(\frac{\partial w}{\partial I_{1}}+\lambda_{1}^{2} \frac{\partial w}{\partial I_{2}}\right) \\
& \sigma_{3}-\sigma_{1}=2\left(\lambda_{3}^{2}-\lambda_{1}^{2}\right)\left(\frac{\partial w}{\partial I_{1}}+\lambda_{2}^{2} \frac{\partial w}{\partial I_{1}}\right)
\end{aligned}
$$

For a single compression test, there is $\sigma_{2}=\sigma_{3}=0, \lambda_{2}^{2}=\lambda_{3}^{2}=\frac{1}{\lambda_{1}}$, hence:

$$
\sigma_{1}=2\left(\lambda_{1}^{2}-\frac{1}{\lambda_{1}}\right)\left(\frac{\partial w}{\partial I_{1}}+\frac{1}{\lambda_{1}} \frac{\partial w}{\partial I_{2}}\right)
$$

Calculating the partial derivatives of Equation (7) with respect to $I_{1}$ and $I_{2}$, respectively, it can be obtained that:

$$
\frac{\partial \mathrm{w}}{\partial I_{1}}=C_{10}, \frac{\partial \mathrm{w}}{\partial I_{2}}=C_{01}
$$

In addition:

$$
\lambda_{1}=1+\varepsilon_{1}
$$

where $\varepsilon_{1}$ is the principal strain (engineering strain) in this direction. Substituting formula (13) and formula (14) into formula (11), it can be obtained that:

$$
\sigma_{1}=C_{10}\left(2+2 \varepsilon_{1}-\frac{2}{\left(1+\varepsilon_{1}\right)^{2}}\right)+C_{01}\left(2-\frac{2}{\left(1+\varepsilon_{1}\right)^{2}}\right)
$$

It can be seen from Equation (15) that the stress-strain relationship is obtained through the material mechanical property test, and the coefficients $C_{10}$ and $C_{01}$ can be determined by the method of least squares fitting.

\subsection{Uniaxial Compression Test of Rubber}

\subsubsection{Sample Preparation}

According to Section 2.1, in order to obtain the material parameters of rubber materials, static mechanical tests of rubber materials were carried out as the next step. The test sample was the rubber cut from the rubber ring buffer, according to the Chinese National Standard, i.e., "GB/T 7757-2009: determination of compressive stress-strain properties of vulcanized rubber or thermoplastic rubber". The sample was made into a cylinder with a diameter of $29 \mathrm{~mm}$ and a height of $12.5 \mathrm{~mm}$, as shown in Figure 2. 


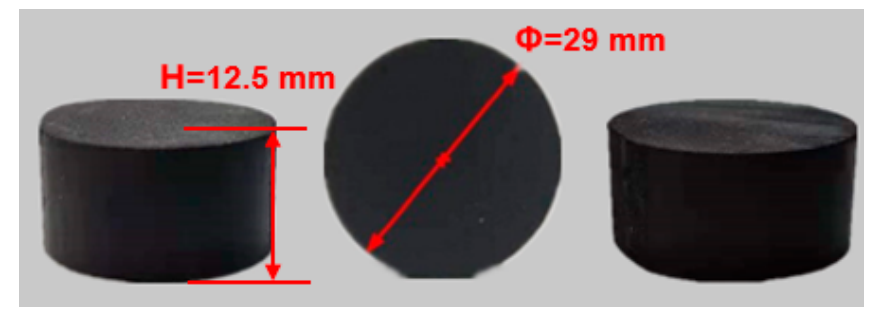

Figure 2. Illustration of the rubber sample.

\subsubsection{Experimental Procedure}

The equipment used in the experiment was the "MTS Insight 30 electronic tension and compression testing machine", as shown in Figure 3. The maximum test force measured was $30 \mathrm{kN}$, and the load accuracy was $\pm 0.5 \%$.

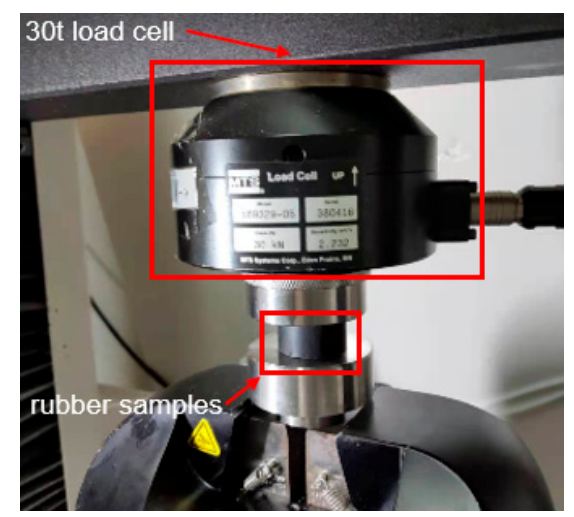

Figure 3. Illustration of the electronic tension and compression testing machine.

Before the initiation of the experiment, a layer of lubricant was firstly attached to the two horizontal surfaces of the rubber to eliminate the influence of friction on the experiment results. The rubber sample was gently placed on the center of the pressure plate. During the test, the sample was compressed at a speed of $10 \mathrm{~mm} / \mathrm{min}$ until the strain reached $60 \%$. Then, the sample was relaxed at the same speed. This loading loop was repeated three times. The purpose of this operation was to eliminate the experimental error caused by the Mullins effect of the rubber material. After that, the formal experiment was conducted. The force during the experiment was measured by the load cell on the top of the pressure plate, and the displacement was obtained by the displacement sensor of the testing machine; thus, the computer could automatically record the force-displacement curve.

\subsubsection{Experiment Results}

The nominal stress-strain curve of the rubber can be obtained by dividing the experimentally measured force by the cross-sectional area of the rubber column, and dividing the displacement by the height of the rubber column. The formal experiments were carried out for three samples, and the arithmetic average of the results is shown in Figure 4. Combining the stress-strain data obtained from the experiment with formula (15) and using the least squares fitting method, the fitting parameters were obtained as, $C_{10}=5.2367, C_{01}=0.2994$. 


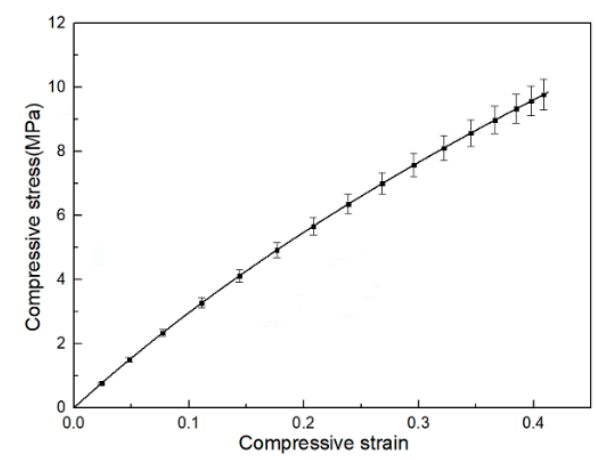

Figure 4. Compressive stress-strain curve of the rubber column.

\subsection{Finite Element Model}

The structure of the rubber buffer is shown in Figure 5. Figure 5a shows the main structure composition and dimensions of the general structure of the rubber ring buffer, which is mainly composed of a front-end plate, rubber ring 1, mounting plate, rubber ring 2, rear end plate, locking nut, and guide column. The length of the guide column is $L=404 \mathrm{~mm}$, and the length, width, and height of the mounting plate are $a=330 \mathrm{~mm}$, $b=520 \mathrm{~mm}$, and $h=60 \mathrm{~mm}$, and the thickness of the rubber ring is $H=90 \mathrm{~mm}$. The rubber ring is installed on both sides of the mounting plate through the guide column. The rubber rings on both sides of the mounting plate have the same shape and size, and their dimensions are shown in Figure $5 \mathrm{~b}$. The inner diameter of the rubber ring is $d=70 \mathrm{~mm}$, the outer rubber circle diameter is $D=184 \mathrm{~mm}$, and the outer contour radius is $R=45 \mathrm{~mm}$.
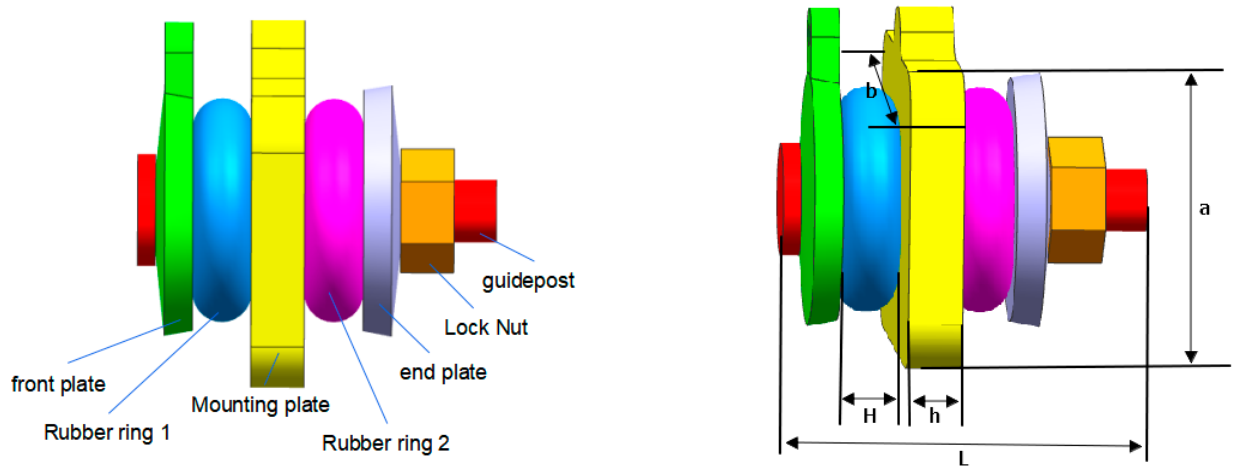

(a)

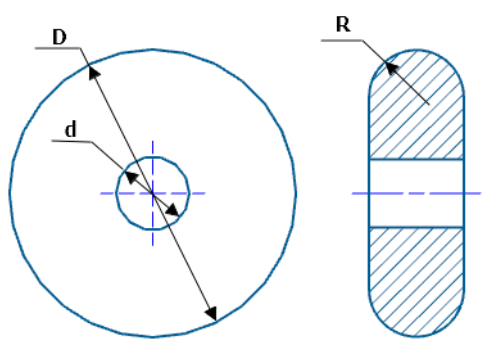

(b)

Figure 5. (a) The main structure composition and size of the rubber ring buffer; (b) rubber ring size.

We used ABAQUS software to establish the finite element model of the rubber buffer. Based on the finite element analysis method, the subsequent calculation was carried out for the longitudinal stiffness of the buffer. The ABAQUS/Explicit module was used to solve the problem. This module is mainly used to analyze the dynamic, quasi-static, and complex nonlinear dynamic problems. When the contact conditions of the system are more 
complicated, this module can solve the problem efficiently. The finite element model of the structure is shown in Figure 6. In the modeling process, shell elements were used for the thin walls and diaphragm, and solid elements were used for the rubber buffers. The welding between the rubber mounting plate and the trolley was simulated by node coupling.

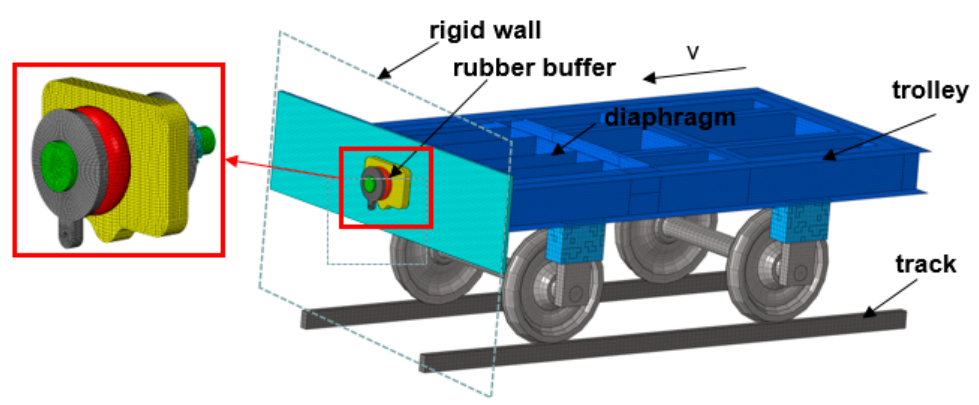

Figure 6. Finite element model.

Since meshing will seriously affect the length of the calculation time and the accuracy of the computational results, especially when meshing materials with large strain characteristics, such as rubber, the contact surface or stress concentration should be appropriately refined to prevent the occurrence of grid distortion, which would lead to analysis failure in the calculation process. In addition, appropriate element types should be selected to simulate each component. For metal materials, C3D8R elements (8-node linear first-order reduction integration elements) are usually used; for rubber materials, C3D8H elements (8-node hexahedral hybrid elements) are the most appropriate, while there are no hybrid elements in the ABAQUS/Explicit solver. However, Reddy et al. [27] pointed out that it is reasonable to use reduced integration elements to simulate nonlinear material properties when using the ABAQUS/Explicit solver. Therefore, we used C3D8R elements to mesh the rubber material. However, the hourglass effect often occurs in the calculation of rubber deformation when using reduced integral units, which can easily lead to inaccurate calculation results or calculation failures. In order to avoid this, the hourglass control enhancement technology was used when meshing. Through the division of each part, the mesh of the rubber buffer model was finally completed. The number of elements and nodes of the finite element model were 120,292 and 130,040, respectively.

The trolley adopts rigid body modeling, and the number of elements and nodes of the finite element model were 50,065 and 60,219, respectively. The rear part of the car was equipped with a mass point for weighting, making the whole car weigh $17 \mathrm{t}$. The whole set of test equipment was placed on the track and the lower side was fixed, hitting the rigid wall at a speed of $5.75 \mathrm{~km} / \mathrm{h}$. In addition to the rubber ring, the trolley and related installation structural materials were set to Q235. The parameters of the relevant materials are shown in Table 1.

Table 1. Material parameters used in the simulation.

\begin{tabular}{ccc}
\hline Parameter & Rubber & Steel \\
\hline${\text { Density } /\left(\mathrm{t} \cdot \mathrm{mm}^{3}\right)}^{3}$ & $1.3 \times 10^{-9}$ & $7.85 \times 10^{-9}$ \\
Young's modulus $/(\mathrm{MPa})$ & $/$ & $2.1 \times 10^{5}$ \\
Poisson's ratio & 0.499 & 0.3 \\
$C_{10} / \mathrm{MPa}$ & 5.2367 & $/$ \\
$C_{01} / \mathrm{MPa}$ & 0.2994 & $/$ \\
\hline
\end{tabular}

In the finite element analysis, this paper used a general contact algorithm to establish the contact relationships among the mounting plate, guide column, surface of the rubber block, surface of the front and rear-end plates, metal surfaces of the mounting plate, guide posts, and surface of the rubber ring serves. According to the actual constraints of the 
buffer, corresponding constraints were set in the non-axial direction of the model, that is, the translation and rotation of the model along the non-axial direction were restricted. The collision simulation time was set to $0.1 \mathrm{~s}$.

\subsection{Validation of FE Model}

In order to verify the validity of the model and correctness of the parameter settings, a dynamic collision test was carried out under the same conditions to obtain the dynamic mechanical properties of rubber ring buffer. The entire test system was mainly composed of a pneumatic launching device that provided a certain speed, force equalizing plate used for impact, $200 \mathrm{t}$ load cell installed between the rigid wall and the equalizing plate to obtain the impact force, and speed measuring instrument that recorded the speed. The collision process of the device was captured by high-speed photography. The related equipment is shown in Figure 7. The high-speed camera shot at a high frame rate of 3000 frames per second, and the sampling frequency of the load cell was 500,000 Hz.

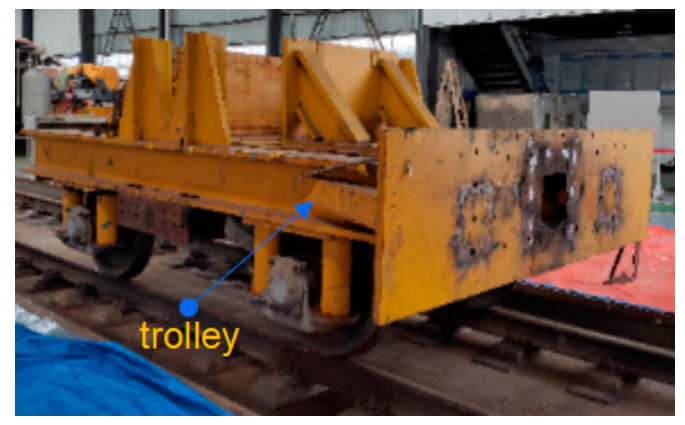

(a)

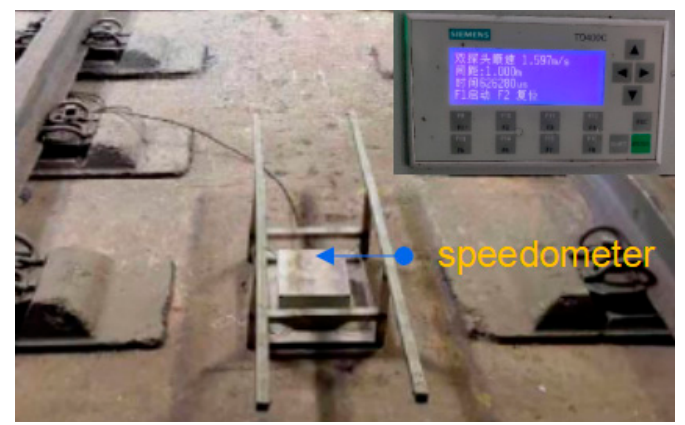

(c)

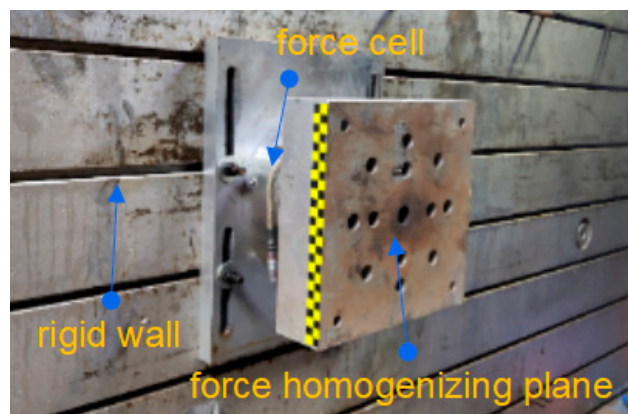

(b)

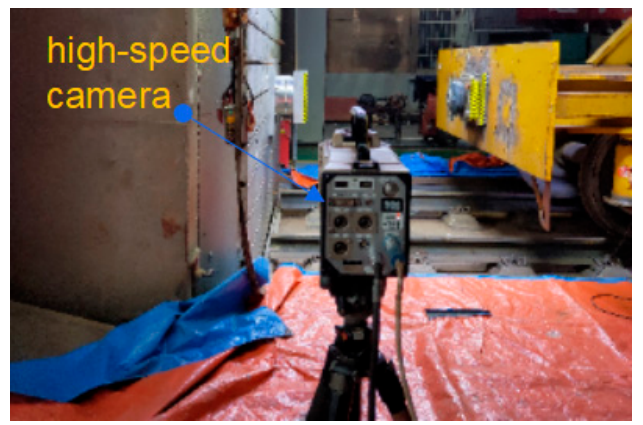

(d)

Figure 7. Experimental scene: (a) trolley; (b) rigid wall and uniform slab; (c) speedmeter; (d) highspeed photography.

High-speed photography captures the collision and deformation modes of the rubber ring at different times. From the comparison between the finite element model and the actual collision diagram at different times in Figure 8, it can be seen that the compression and deformation modes of the rubber ring are basically the same.

The displacement-time curve obtained by high-speed photography and the force-time curve obtained by the force sensor were compared with the simulation results, as shown in Figure 9a,b. The beginning of the test is the time when the rubber buffer and the rigid wall began to contact. It can be seen from the figure that the force value of the rubber buffer gradually increased with the compression of the buffer. When the buffer was compressed to the limit state, a peak force formed; as the trolley rebounded, the final force value gradually returned to 0 . In the experiment, the amount of compression of the rubber was obtained by taking high-speed photography to capture the points on the scale paper positioned with paste on the mounting plate, and the amount of displacement and compression was basically consistent with the simulation. The force-displacement curve was obtained by 
combining the force-time and displacement-time curves, as shown in Figure 9c. It can be seen from the figure that these curves are in good agreement. Table 2 shows the relative error between the experiment and simulation.
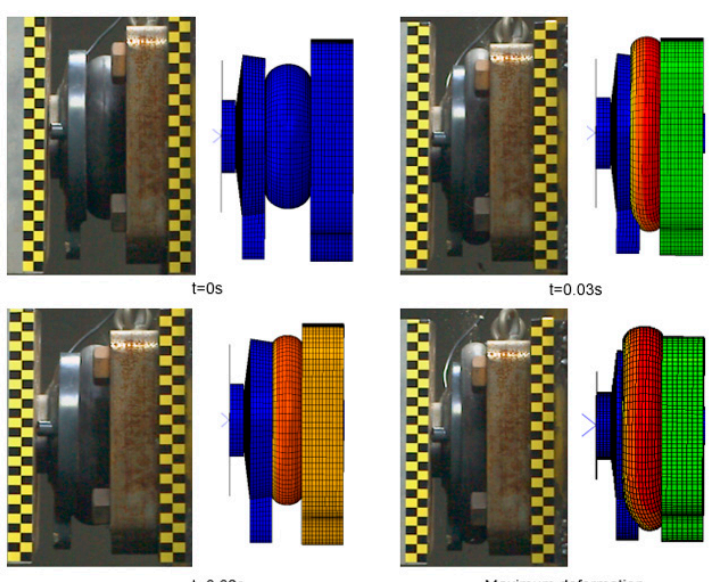

Figure 8. Comparison of the deformation process between the experimental and simulation results.

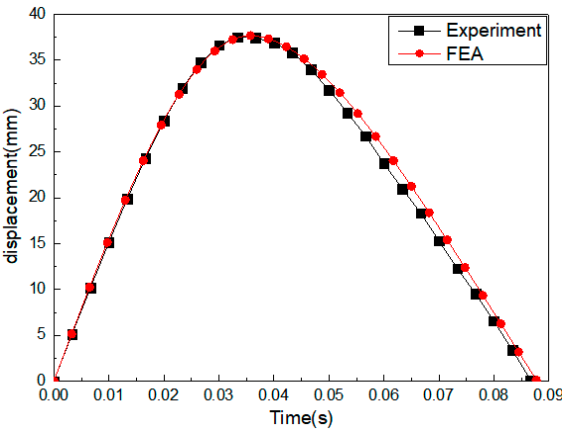

(a)

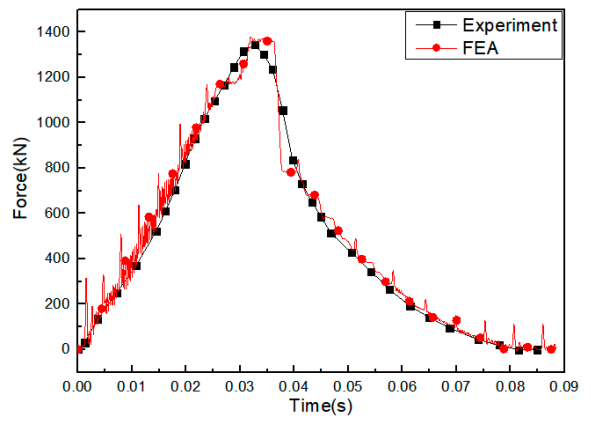

(b)

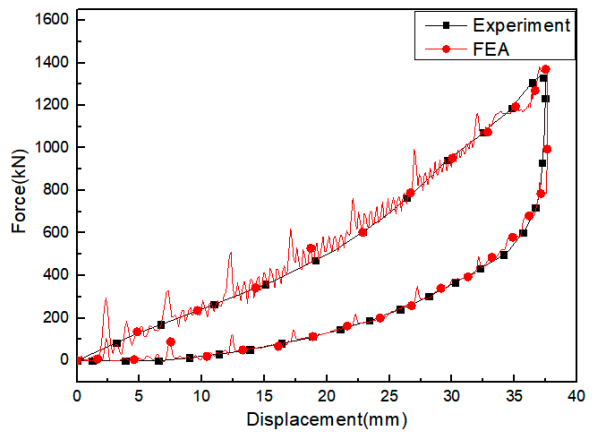

(c)

Figure 9. Experiment and simulation comparison: (a) Displacement-time curve; (b) force-time curve; (c) force-displacement curve.

Table 2. The relative error between the experiment and simulation.

\begin{tabular}{cccc}
\hline & $\begin{array}{c}\text { Amount of } \\
\text { Compression (mm) }\end{array}$ & $\begin{array}{c}\text { Peak } \\
\text { Force (kN) }\end{array}$ & $\begin{array}{c}\text { Energy } \\
\text { Absorption (kJ) }\end{array}$ \\
\hline Experiment Data & 37.52 & 1342.99 & 13.23 \\
Finite element & 37.66 & 1380 & 14.09 \\
analysis & $-0.37 \%$ & $2.76 \%$ & $6.5 \%$ \\
Relative error & & & \\
\hline
\end{tabular}


In summary, the force-displacement curves and structural deformation modes of the test and simulation output are in good agreement, and the relative error is within 10\%, indicating that the simulation model is credible and can be used for subsequent parameter research and optimization.

\section{Parametric Analysis}

\subsection{Structural Crashworthiness Criteria}

Figure $9 \mathrm{c}$ is the force-displacement curve of a typical rubber buffer under an axial impact load. In order to evaluate the energy absorption of the rubber buffer under axial load, the energy absorption $E A$, maximum impact force $F_{m a x}$, and specific energy absorption $S E A$ were selected as the evaluation criteria. Among them, the energy absorption $E A$ is an important criterion for judging the energy absorption capacity of energy absorbers. The formula is defined as:

$$
E A=\int_{0}^{x} F(x) d x
$$

where $x$ is the effective compression displacement of the rubber, and $F(x)$ is the instantaneous collision force that changes with the displacement. The specific energy absorption $S E A$ is the energy absorption per unit mass of the energy absorbing structure, which is defined by the formula:

$$
S E A=\frac{E A}{M}
$$

where $M$ is the mass of the energy absorber. The greater the specific energy absorption $S E A$, the better the energy absorption effect of the energy absorber.

\subsection{The Influence of the Height Parameter $H$ on the Rubber Ring under Different Ratios of $C_{01} / C_{10}$}

In order to study the effect of the height $H$ of the rubber ring on the energy absorption and peak impact force of the rubber buffer under different ratios of $C_{01} / C_{10}$, keeping the outer contour radius of the rubber buffer unchanged, $R=55 \mathrm{~mm}$ and $C_{10}=5.2367$ were set, and $C_{01} / C_{10}=0.057,0.157,0.257,0.357,0.457, H=70 \mathrm{~mm}, 80 \mathrm{~mm}, 90 \mathrm{~mm}$, $100 \mathrm{~mm}, 110 \mathrm{~mm}$, respectively. Under different $C_{01} / C_{10}$ ratios, the impact of different rubber ring heights on the mechanical properties of the buffer is shown in Figure 10. It can be seen from the figure that under the same $C_{01} / C_{10}$ ratio, as the rubber ring height $H$ increased, the energy absorption of the buffer gradually increased first, when the height of the rubber ring reached $100 \mathrm{~mm}$, the energy absorption dropped suddenly. The specific energy absorption gradually decreased with the increase of the rubber ring height and the peak force gradually decreased with the increase of the rubber ring height and gradually stabilized. Under different $C_{01} / C_{10}$ ratios, as the $C_{01} / C_{10}$ ratio increased, the energy absorption and specific energy absorption both showed a decreasing trend, while the peak force gradually increased with the increase of the ratio of $C_{01} / C_{10}$.

\subsection{The Influence of the Outer Contour Parameter $R$ of the Rubber Ring}

In order to study the influence of the outer contour parameter $R$ of the rubber ring on the energy absorption and peak impact force of the rubber buffer under different ratios of $C_{01} / C_{10}$, keeping the height of the rubber buffer unchanged, $H=90 \mathrm{~mm}, C_{10}=5.2367$ and $C_{01} / C_{10}=0.057,0.157,0.257,0.357,0.457, R=50 \mathrm{~mm}, 60 \mathrm{~mm}, 70 \mathrm{~mm}, 80 \mathrm{~mm}, 90 \mathrm{~mm}$, respectively. Under different ratios of $C_{01} / C_{10}$, the effect of the outer contour radius $R$ of different rubber rings on the mechanical properties of the buffer is shown in Figure 11. It can be seen from the figure that under the same ratio of $C_{01} / C_{10}$, as the outer contour radius $R$ of the rubber ring increased, the energy absorption and specific energy absorption of the buffer gradually increased, and the peak force decreased slowly with the increase of the radius $R$ of the outer contour of the rubber ring. Under different $C_{01} / C_{10}$ ratios, as the ratio of $C_{01} / C_{10}$ increased, the energy absorption and specific energy absorption 
gradually decreased, while the peak force gradually increased with the increase of the ratio of $C_{01} / C_{10}$.

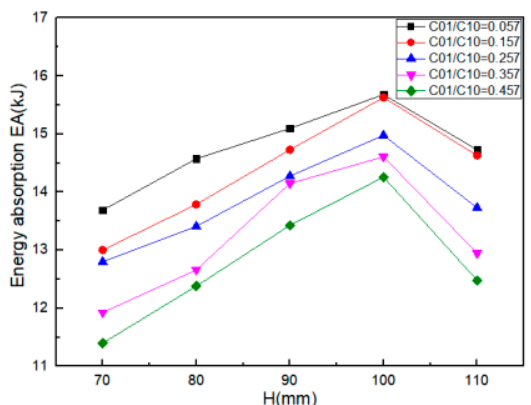

(a)

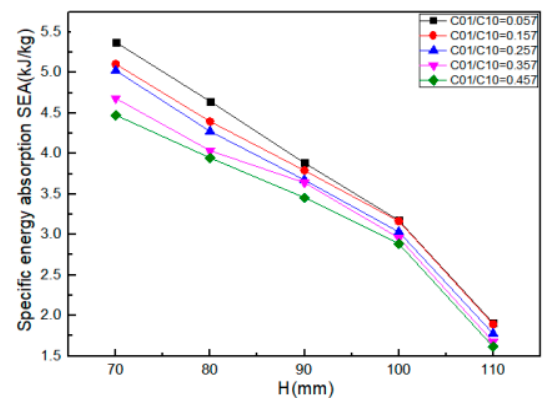

(b)

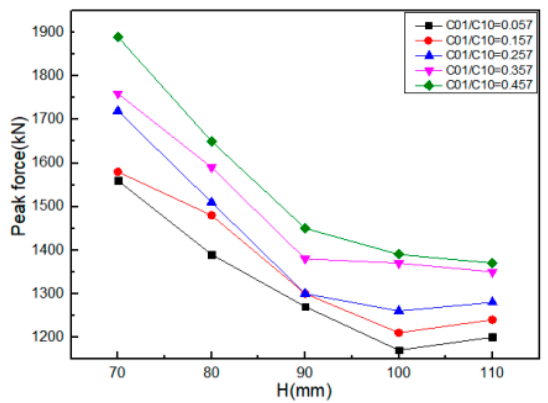

(c)

Figure 10. Comparison of the same contour radius at different heights and different $C_{01} / C_{10}$ ratios: (a) Energy absorption; (b) Specific energy absorption; (c) Peak force.

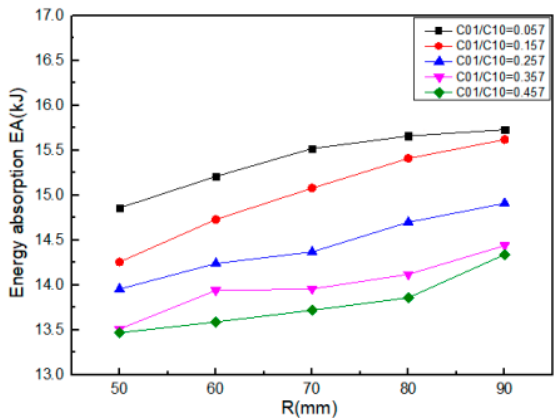

(a)

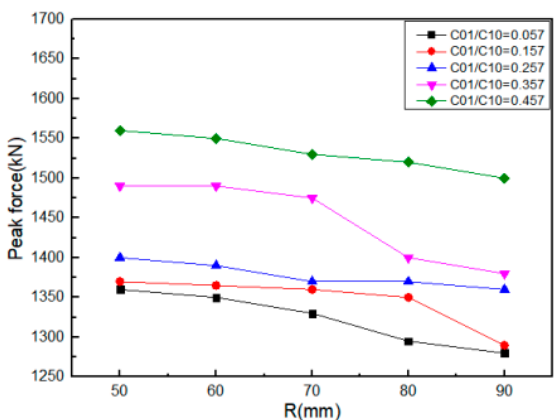

(c)

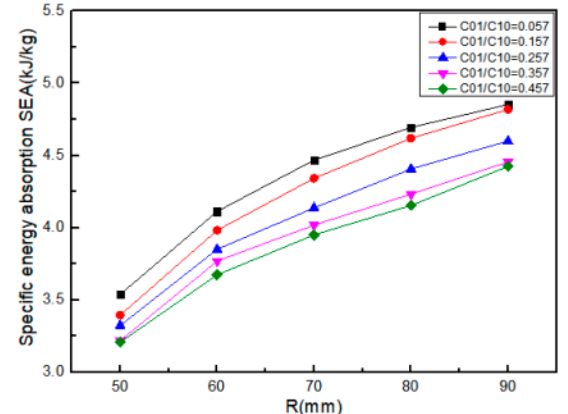

(b)

Figure 11. Comparison of the same height, under different contour radii and different $C_{01} / C_{10}$ ratios: (a) Energy absorption; (b) specific energy absorption; (c) peak force. 


\section{Multi-Objective Optimization}

\subsection{Experimental Design}

In order to optimize the mechanical properties of the rubber buffer and reduce the amount of calculation for simulation optimization, the response surface method was used here to optimize the design. In the construction of the response surface, the selection of test points is very important. Arbitrarily selected test points will lead to inaccurate response surfaces or even a failure to construct response surfaces. The theory of experimental design can help determine reasonable design points. The optimized Latin hypercube experimental design has the characteristics of high efficiency, good accuracy, and a uniform distribution, which can provide excellent test sample points for the response surface model. Therefore, this paper adopted the optimized Latin hypercube experimental design method to construct the response surface model. The optimized Latin hypercube test method was used to design 30 sets of experiments on the three variables of $C_{01} / C_{10}$ ratio, buffer height $H$, and buffer contour radius $R$. The $C_{01} / C_{10}$ ratio distribution interval was [0.057, 0.457], the buffer height $H$ distribution interval was [70,110], and the buffer contour radius $R$ distribution interval was [50,90], with $C_{10}=5.2367$. The specific energy absorption $S E A$ of the rubber buffer and the maximum peak force $F_{\max }$ were used as the optimization goals, and the 30 sets of test samples obtained were calculated by the ABAQUS software to obtain the results of the optimization goals. The experimental design and results are shown in Table 3.

Table 3. Experimental design and numerical results.

\begin{tabular}{|c|c|c|c|c|c|}
\hline $\begin{array}{l}\text { Serial Number } \\
\text { Parameter }\end{array}$ & $C_{01} / C_{10}$ & $H(\mathrm{~mm})$ & $R(\mathrm{~mm})$ & $\begin{array}{c}S E A \\
(\mathrm{~kJ} / \mathrm{kg})\end{array}$ & $F_{\max }(\mathbf{k N})$ \\
\hline 1 & 0.154 & 110.00 & 78.97 & 3.5016 & 1170 \\
\hline 2 & 0.126 & 83.79 & 90.00 & 5.1202 & 1370 \\
\hline 3 & 0.25 & 100.34 & 52.76 & 2.8426 & 1300 \\
\hline 4 & 0.319 & 89.31 & 58.28 & 3.7419 & 1380 \\
\hline 5 & 0.098 & 104.48 & 56.90 & 2.9625 & 1170 \\
\hline 6 & 0.402 & 94.83 & 69.31 & 3.6179 & 1380 \\
\hline 7 & 0.416 & 101.72 & 84.48 & 3.3886 & 1310 \\
\hline 8 & 0.112 & 90.69 & 50.00 & 3.4406 & 1370 \\
\hline 9 & 0.333 & 70.00 & 63.79 & 4.8986 & 1750 \\
\hline 10 & 0.388 & 71.38 & 80.34 & 4.9943 & 1710 \\
\hline 11 & 0.223 & 107.24 & 65.17 & 2.8544 & 1190 \\
\hline 12 & 0.305 & 82.41 & 72.07 & 4.3268 & 1480 \\
\hline 13 & 0.457 & 93.45 & 55.52 & 3.2324 & 1410 \\
\hline 14 & 0.085 & 98.97 & 70.69 & 3.8219 & 1170 \\
\hline 15 & 0.181 & 92.07 & 62.41 & 3.6437 & 1320 \\
\hline 16 & 0.429 & 86.55 & 81.72 & 3.9333 & 1410 \\
\hline 17 & 0.057 & 75.52 & 77.59 & 5.3564 & 1420 \\
\hline 18 & 0.14 & 97.59 & 85.86 & 4.1715 & 1180 \\
\hline 19 & 0.36 & 76.9 & 51.38 & 3.8586 & 1600 \\
\hline 20 & 0.167 & 85.17 & 76.21 & 4.6188 & 1370 \\
\hline 21 & 0.443 & 79.66 & 66.55 & 4.2685 & 1570 \\
\hline 22 & 0.291 & 87.93 & 87.24 & 4.3014 & 1370 \\
\hline 23 & 0.278 & 103.1 & 88.62 & 3.9395 & 1210 \\
\hline 24 & 0.374 & 105.86 & 59.66 & 2.6384 & 1350 \\
\hline 25 & 0.236 & 74.14 & 83.1 & 5.2921 & 1560 \\
\hline 26 & 0.209 & 78.28 & 54.14 & 4.38591 & 1450 \\
\hline 27 & 0.071 & 81.03 & 61.03 & 4.60181 & 1360 \\
\hline 28 & 0.195 & 72.76 & 67.93 & 4.9175 & 1560 \\
\hline 29 & 0.264 & 96.21 & 74.83 & 3.7040 & 1320 \\
\hline 30 & 0.347 & 108.62 & 73.45 & 3.0544 & 1300 \\
\hline
\end{tabular}

In order to analyze the influence of the design variables constitutive parameter $C_{01} / C_{10}$, rubber ring thickness $H$, and contour radius $R$ on the buffer performance, the 
main effect results were analyzed. The main effects analysis only considers the influence of a single design variable on the response, and does not consider other design variables. The greater the absolute value of the main effect result, the greater the influence of the variable on the result of the response. Table 4 lists the impact analysis of the main effect results.

Table 4. Analysis of main effect results.

\begin{tabular}{ccc}
\hline & $S E A(\mathbf{k J} / \mathbf{k g})$ & $\boldsymbol{F}_{\text {max }}(\mathbf{k N})$ \\
\hline$C_{01} / C_{10}$ & -0.588 & 211.9 \\
$H$ & -2.13 & -434.7 \\
$R$ & 1.09 & -61.0 \\
\hline
\end{tabular}

It can be seen from the table that the height of the rubber ring has the greatest influence on the main effect. The main effect of the height of the rubber ring on the specific energy absorption $S E A$ is 3.62 and 1.95 times the constitutive parameters $C_{01} / C_{10}$ and the radius of the rubber ring contour, respectively. The main effect of $H$ on the maximum peak force $F_{\max }$ is 2.05 and 7.13 times the constitutive parameter $C_{01} / C_{10}$ and the radius $R$ of the rubber ring, respectively. The main effect of the constitutive parameter $C_{01} / C_{10}$ on the maximum peak force $F_{\max }$ is larger than the radius $R$ of the rubber ring, while the influence of the radius $R$ on the main effect of energy absorption SEA is larger than that of the constitutive parameters $C_{01} / C_{10}$.

\subsection{Surrogate Model}

Based on the results of the optimized Latin hypercube test design, the response surface method was used to construct a response surface model of specific energy absorption and maximum peak force. Figure 12 shows the response surface model of specific energy absorption $S E A$ and maximum peak force $F_{\max }$ at different constitutive parameters $C_{01} / C_{10}$, rubber ring height $H$, and outer contour radius $R$. It can be seen from the figure that as the height $H$ of the rubber ring increased, the peak force of the rubber ring and the specific energy absorption $S E A$ both showed a decreasing trend. As the radius $R$ of the outer contour of the rubber ring increased, the peak force of the rubber ring slowly decreased, while the specific energy absorption SEA gradually increased. As the ratio of the constitutive parameter $C_{01} / C_{10}$ of the rubber ring increased, the peak force of the rubber ring increased, and the specific energy absorption SEA showed a slow decreasing trend. The proxy model equations for the specific energy absorption and maximum peak force of the rubber ring are shown in (18) and (19). To simplify the equation, $C_{01} / C_{10}=L$ :

$$
\begin{gathered}
S E A=73.228-6.428 \mathrm{~L}-3.372 \mathrm{H}+0.4339 \mathrm{R}+39.626 \mathrm{~L}^{2}+0.0555 \mathrm{H}^{2}-0.00692 \mathrm{R}^{2} \\
+0.01473 \mathrm{LH}-0.03298 \mathrm{LR}+0.00033 \mathrm{HR}-112.842 \mathrm{~L}^{3}-0.000414 \mathrm{H}^{3} \\
+4.481 \times 10^{-5} \mathrm{R}^{3}+112.785 \mathrm{~L}^{4}+1.1568 \times 10^{-6} \mathrm{H}^{4}-8.9768 \times 10^{-8} \mathrm{R}^{4} \\
F_{\text {max }}= \\
+76,443.585+2874.934 \mathrm{~L}-2374.689 \mathrm{H}-1206.435 \mathrm{R}-19,819.206 \mathrm{~L}^{2}+38.973 \mathrm{H}^{2} \\
+26.198 \mathrm{R}^{2}+4.1861 \mathrm{LH}-0.8362 \mathrm{LR}-0.08619 \mathrm{HR}+58,524.713 \mathrm{~L}^{3}-0.2847 \mathrm{H}^{3} \\
-0.2487 \mathrm{R}^{3}-59,339.25 \mathrm{~L}^{4}+0.000779 \mathrm{H}^{4}+0.000876 \mathrm{R}^{4}
\end{gathered}
$$



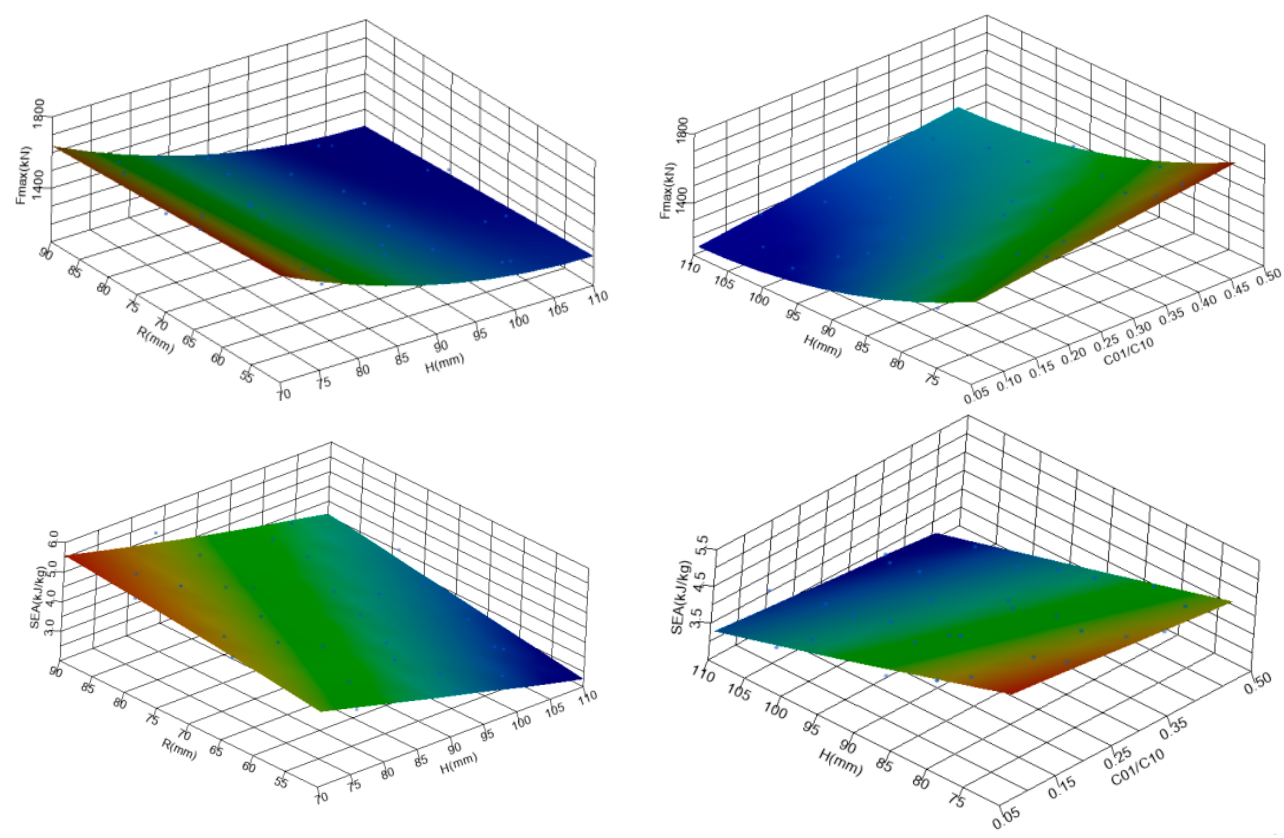

Figure 12. Response surface analysis diagram of $S E A$ and $F_{\text {max }}$.

In order to evaluate the correctness of the proxy model, the relative error $R E$, root mean square error RMSE, maximum absolute error, and $R^{2}$ value were used to evaluate the error between the proxy model and the numerical simulation calculation results [28]. The error expression is shown in (20)-(23):

$$
\begin{gathered}
R E=\frac{y(x)-\widetilde{y}(x)}{y(x)} \\
R M S E=\sqrt{\frac{\sum_{i=1}^{n}\left(y_{i}-\widetilde{y}_{i}\right)^{2}}{n}} \\
M A X=\max \left|y_{i}-\widetilde{y}_{i}\right|, i=1,2, \ldots \ldots n \\
R^{2}=1-\frac{\sum_{i=1}^{n}\left(y_{i}-\widetilde{y}_{i}\right)^{2}}{\sum_{i=1}^{n}\left(y_{i}-\bar{y}_{i}\right)^{2}}
\end{gathered}
$$

where $n$ is the number of design sample points, and $\widetilde{y}(x)$ and $y(x)$ are the calculated values of the surrogate model and the finite element model, respectively. When the value of $M A X$ and RMSE is smaller or the value of $R^{2}$ is larger, it indicates that the accuracy of the surrogate model is higher. The error analysis of the surrogate model is shown in Table 5. It can be seen from the table that the surrogate model has high accuracy, which lays the foundation for the next optimization design.

Table 5. Error analysis of the surrogate model.

\begin{tabular}{ccccc}
\hline Function & RMSE & MAX & $\boldsymbol{R}^{\mathbf{2}}$ & $\boldsymbol{R E}(\%)$ \\
\hline$S E A(\mathrm{~kJ} / \mathrm{kg})$ & 0.078 & 0.15 & 0.94 & $(-5.07,3.51)$ \\
$F_{\max }(\mathrm{kN})$ & 0.073 & 0.13 & 0.93 & $(-3.94,5.35)$ \\
\hline
\end{tabular}

\subsection{Optimization Method}

The functional relationship between the specific energy absorption, maximum impact force, and ratio of the constitutive parameters $C_{01} / C_{10}$ of the rubber ring, the height $H$, 
and the outer contour radius $R$ was constructed through the response surface model, in order to obtain a higher specific energy absorption and a lower peak value. It is necessary to optimize the proxy model to find the best rubber ring constitutive parameter $C_{01} / C_{10}$ ratio, height $H$, and outer contour radius $R$, and the boundary of specific energy absorption and the maximum peak force were determined by the test values. In this paper, the nondominated sorting multi-objective genetic algorithm (NSGA-II) was used to solve the multi-objective optimization problem. The optimization objective function is:

$$
\left\{\begin{array}{l}
\operatorname{Min}\left\{-S E A, F_{\text {max }}\right\} \\
70 \leq H \leq 110 ; 50 \leq R \leq 90 ; 0.057 \leq C_{01} / C_{10} \leq 0.457 \\
S E A>2.38, F_{\text {max }}<1342.99
\end{array}\right.
$$

The multi-objective genetic algorithm was used to solve the optimal value of the surrogate model. First, the initial population was randomly generated and the objective function value and constraint function value of each point were calculated. Next, the population was sorted non-dominantly according to the objective function value, and constraint penalties, poor solution penalties, and total penalties were calculated for each point according to the constraint function value and grading result. Then, the crowding degree based on the total penalty for each point was calculated and selection, crossover and mutation operations, and population merging performed. Then, the constraint penalties, poor solution penalties, and total penalties of each point were calculated again according to the constraint function value and the classification result, and the crowding degree was calculated based on the total penalty of each point to generate a new group. The termination conditions were determined and the pareto optimal solution set and the corresponding objective function value were output in the candidate table. Finally, the most suitable problem solution from the pareto optimal set was selected. The flow chart of the multi-objective genetic algorithm is shown in Figure 13, and the specific parameters of the surrogate model used in this paper are shown in Table 6.

\subsection{Optimization Results}

In order to verify the correctness of the finite element model, this paper studied the minimum peak force and maximum specific energy absorption that the structure can achieve under certain constraints. According to the initial calculation results, SEA was set to be no less than $2.38 \mathrm{~kJ} / \mathrm{kg}$, and $F_{\text {max }}$ was no more than $1342.99 \mathrm{kN}$. Figure 14 shows the comparison of the experiment results and simulation results after parameter optimization and the Pareto-front solution for $-S E A$ and $F_{\max }$. Table 7 shows the multiobjective optimization results, finite element calculation results, and comparative error analysis. The errors of $S E A$ and maximum peak force $F_{m a x}$ were both below $10 \%$, indicating that the optimization results have relatively high accuracy.

Table 6. NSGA-II algorithm tables and figures.

\begin{tabular}{cc}
\hline Parameter & Value \\
\hline Population size (multiples of 4) & 20 \\
Number of generations & 50 \\
Crossover probability & 0.9 \\
Crossover distribution index & 10 \\
Mutation distribution index & 20 \\
Maximum number of failed runs & 5 \\
\hline
\end{tabular}




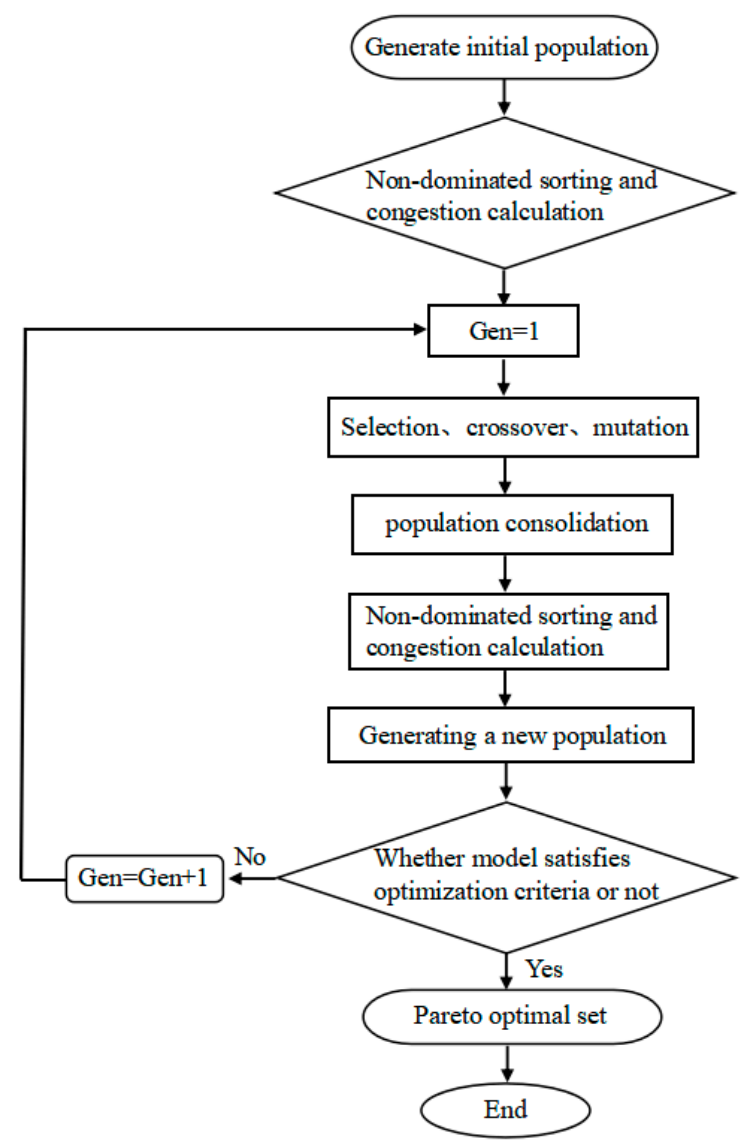

Figure 13. Flow chart of the NSGA-II genetic algorithm.

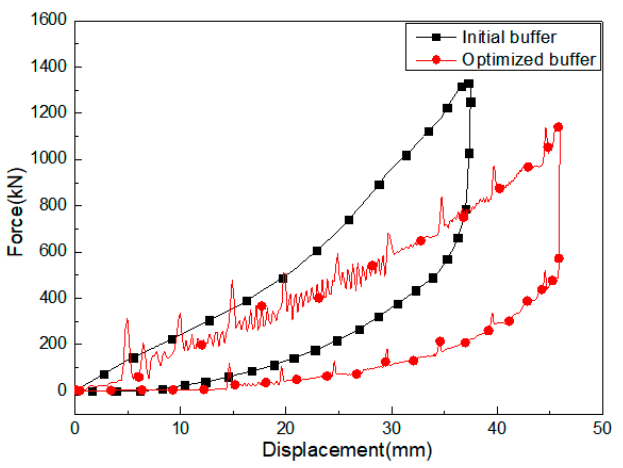

(a)

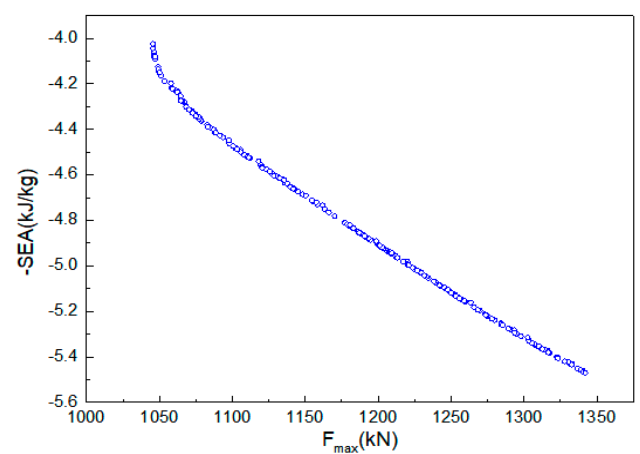

(b)

Figure 14. (a) Comparison of the experiment results and simulation results after parameter optimization; (b) Pareto-front solution for $-S E A$ and $F_{\max }$.

Table 7. Optimization results of minimizing $F_{\max }$ with the $S E A$ constraint.

\begin{tabular}{|c|c|c|c|c|c|c|}
\hline \multirow{2}{*}{ Design Variables } & \multicolumn{2}{|c|}{ NSGA-II } & \multicolumn{2}{|c|}{ FEA Result } & \multicolumn{2}{|c|}{ Accuracy } \\
\hline & $S E A(\mathrm{~kJ} / \mathrm{kg})$ & $F_{\max }(\mathbf{k N})$ & $S E A(\mathbf{k J} / \mathbf{k g})$ & $F_{\max }(\mathbf{k N})$ & $R E_{S E A}(\%)$ & $R E_{\text {Fmax }}(\%)$ \\
\hline $\begin{array}{c}H=107.57 \mathrm{~mm} \\
R=85.70 \mathrm{~m} \\
C_{01} / C_{10}=0.0571\end{array}$ & 4.02 & 1045.57 & 3.78 & 1150 & 6.35 & -9.08 \\
\hline
\end{tabular}

In summary, the general design process of rubber buffer is shown in Figure 15. 


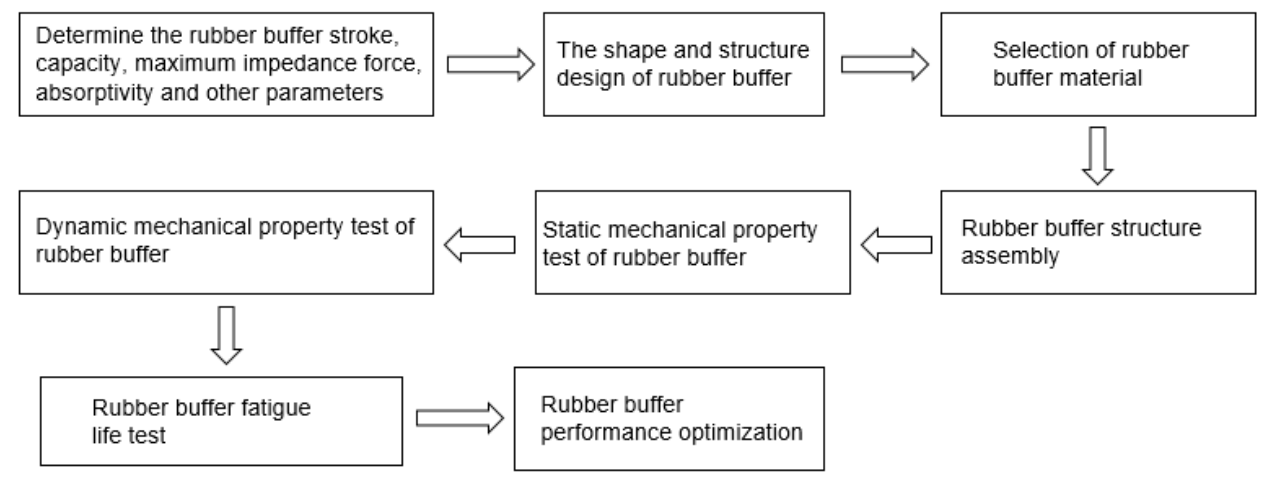

Figure 15. General design process of rubber buffer.

\section{Conclusions}

This paper studied the influence of relevant parameters of rubber ring buffer on its energy-absorption characteristics. The experimental design was carried out by using the optimized Latin hypercube experimental design method, and the response surface model was constructed to directly express the influence of rubber ring parameters on its mechanical properties. On the basis of the agent model, the non-dominated genetic algorithm NSGA-II was used to optimize the rubber ring quickly, which avoided the long calculation time and low optimization efficiency of the traditional finite element method. The SEA error and the maximum impact force error $F_{\max }$ of the pareto-front front solution were both within $10 \%$, which verifies the accuracy of the optimization and the effectiveness of the method. It shows that construction of the proxy model can help to search for optimization quickly and has certain reference value in engineering. The main findings of this study are summarized as follows:

(1) On the premise that the contour radius $(R)$ of the rubber ring is fixed, the $S E A$ and the $F_{\max }$ gradually decrease with the increase of the rubber ring height. The $S E A$ also gradually decreases with the increase of $C_{01} / C_{10}$, while the $F_{\max }$ gradually increases with the increase of $C_{01} / C_{10}$.

(2) On the premise that the height $(H)$ of the rubber ring is fixed, the SEA gradually increases with the increase of the contour radius, and the $F_{\max }$ decreases slowly with the increase of the contour radius. However, the $S E A$ gradually decreases with the increase of the $C_{01} / C_{10}$, while the $F_{\text {max }}$ gradually increases with the increase of the $C_{01} / C_{10}$. The rubber height $(H)$ takes the main effect on both the specific energy absorption and the maximum peak force.

(3) In order to maximize $S E A$ and minimize $F_{m a x}$, the response surface model was constructed and the non-dominated genetic algorithm NSGA-II was used to optimize the rubber ring quickly. The Pareto-front solution was obtained for the rubber ring buffer. When $H=107.57 \mathrm{~mm}, R=85.70 \mathrm{~mm}$, and $C_{01} / C_{10}=0.0571$, the energy absorption of the optimized buffer was increased by $59.03 \%$ and the peak force decreased by $14.37 \%$, compared with the original structure.

Author Contributions: Conceptualization, C.Q. and P.X.; methodology, C.Q., P.X. and C.Y.; investigation, C.Q. and A.W.; resources, C.Q. and S.Y.; data curation, C.Q. and C.Y.; writing-original draft preparation, C.Q. and C.Y.; writing-review and editing, C.Q. and C.Y.; project administration, P.X.; funding acquisition, P.X. All authors have read and agreed to the published version of the manuscript.

Funding: This research was funded by the National Key Research and Development Program of China, grant number 2016YFB1200505-016, and the Scientific Research Foundation for Young Scholars of Central South University (No. 202044019).

Institutional Review Board Statement: Not applicable.

Informed Consent Statement: Not applicable.

Data Availability Statement: Not applicable. 
Conflicts of Interest: The authors declare no conflict of interest.

\section{Nomenclature}

$\begin{array}{ll}C_{01}, C_{10} & \begin{array}{l}\text { Constitutive parameters of rubber materials } \\ I_{1}, I_{2}, I_{3}\end{array} \\ \lambda_{1}, \lambda_{2}, \lambda_{3} & \text { three invariants of deformation tensor of strain energy density function } \\ \text { W } & \begin{array}{l}\text { strain energy density function } \\ \text { principal stress of rubber material }\end{array} \\ \sigma \mathrm{i} & \begin{array}{l}\text { pressure } \\ \mathrm{P}\end{array} \\ \mathcal{E} & \text { principal strain } \\ \Phi & \text { diameter } \\ \mathrm{L} & \text { length of guide column for rubber buffer } \\ \mathrm{a}, \mathrm{b}, \mathrm{h} & \text { length, width and height of rubber buffer mounting plate } \\ H & \text { thickness } \\ \mathrm{d} & \text { diameter of inner hole of rubber ring } \\ \mathrm{D} & \text { diameter of rubber circle outside rubber ring } \\ R & \text { outer contour radius of rubber ring } \\ F_{\text {max }} & \text { maximum peak force }\end{array}$

\section{References}

1. Lim, S.; Ji, Y.H.; Park, Y.I. Simulation of energy absorption performance of the couplers in urban railway vehicles during a heavy collision. Machines 2021, 9, 91. [CrossRef]

2. Wu, J.; Liu, Q.; Wang, Y.S. Finite element simulation on tire rubber extrusion process. Adv. Mater. Res. 2013, $2337,548-551$. [CrossRef]

3. Wang, Q.; Xiao, X.; Luo, R. Optimum design of wheeled loader's steering rubber buffer seat based on ANSYS. Adv. Mater. Res. 2011, 1169, 1217-1222. [CrossRef]

4. Zhang, Z.; Li, G.; Chu, G. Compressed stability analysis of the coupler and buffer system of heavy-haul locomotives. Veh. Syst. Dyn. 2015, 53, 833-855. [CrossRef]

5. Shang, B.; Lu, H.; Shi, J. Finite element analysis of static elastic characteristics of the rubber isolators in automotive dynamic systems. SAE Trans. 2003, 112, 185-193.

6. Peng, B.; Wang, N.; Yu, T. Influences of dimension parameters on the compression performance of FRP rubber bearings. Adv. Mater. Res. 2011, 1279, 977-981. [CrossRef]

7. Pang, H.; Li, H.Y.; Fang, Z.D.; Zhu, X.Y. Finite element analysis of mechanical characteristics on the composite rubber suspension of heavy vehicle. Appl. Mech. Mater. 2012, 1498, 1702-1706. [CrossRef]

8. Tao, X.; Wang, P.; Ma, X. Numerical mechanical analysis of filled rubber under different deformation states based on a new hyperelastic constitutive model. Mater. Sci. Forum. 2021, 6181, 15-22.

9. Freakley, P.K.; Payne, A.R. Theory and Practice of Engineering with Rubber; Applied Science Publishers: London, UK, 1978.

10. Zhang, L.; Wei, H. A novel structure of rubber ring for hydraulic buffer seal based on numerical simulation. Appl. Sci. 2021, 11, 87-102.

11. Mariusz, S.; Dzialak, P.; Zedzianowski, B. Numerical and experimental analysis of the rubber bumper stiffness. Mater. Today Proc. 2019, 12, 508-513.

12. Shi, S.X.; Yang, J.L. Large deformation of incompressible rubber cylinder under plane strain. Acta Mech. Solida Sin. 1999, 12, 348-355.

13. Yildiz, F. The effect of different strain energy functions on rubber fender. J. Elastomers Plast. 2014, 46, 722-736. [CrossRef]

14. Wang, S.W.; Wang, W.D.; Zhou, D.M. Rubber joint for fatigue crack factors numerical analysis of certain vehicle. Appl. Mech. Mater. 2011, 1326, 1505-1508. [CrossRef]

15. Xue, X.; Robinson, M.; Schmid, F. Development issues for impact safety of rail vehicles: Robustness of crashworthy designs, effect of structural crashworthiness on passenger safety and behaviour characterisation of vehicle materials. J. Rail Rapid Transit 2018, 232, 461-470. [CrossRef]

16. Afazov, S.; Denmark, W.; Yaghi, A. Modelling aspects of the design of railway vehicle structures and their crashworthiness. J. Rail Rapid Transit 2016, 230, 1575-1589. [CrossRef]

17. Yang, L.; Kang, Y.; Luo, S. Assessment of the curving performance of heavy haul trains under braking conditions. J. Modern Trans. 2015, 23, 169-175. [CrossRef]

18. Li, D.; Mao, Y.; Xu, K. A SHPB experimental study on dynamic mechanical property of high-damping rubber. Shock. Vib. 2018, 2018, 55-64. [CrossRef]

19. Yao, G.; Li, X. Experimental investigation of the quasi-static and impact tests on the energy absorption characteristics of coupler rubber buffers used in railway vehicles. J. Rail Rapid Transit. 2019, 233, 937-950. [CrossRef] 
20. Zhang, W.; Zheng, F.; Liu, C. Energy absorption ratio of rubber material under dynamic impact load. Ordnance Mater. Sci. Eng. 2012, 35, 19.

21. Chen, Y.; Zhang, B.; Zhang, N.; Zheng, M. A condensation method for the dynamic analysis of vertical vehicle-track interaction considering vehicle flexibility. J. Vib. Acoust. 2015, 13, 41010. [CrossRef]

22. Cui, X.; He, Z.; Huang, B.; Chen, Y.; Du, Z.; Qi, W. Study on the effects of wheel-rail friction self-excited vibration and feedback vibration of corrugated irregularity on rail corrugation. Wear 2021, 477, 203854. [CrossRef]

23. Chen, Y.; Zhang, B.; Chen, S. Model reduction technique tailored to the dynamic analysis of a beam structure under a moving load. Shock. Vib. 2014, 2014, 406093. [CrossRef]

24. Mooney, M. A theory of large elastic deformation. J. Appl. Phys. 1940, 11, 582-592. [CrossRef]

25. Yeoh, O.H. Some forms of the strain energy function for rubber. Rubber Chem. Technol. 1993, 66, 754-771. [CrossRef]

26. Sussman, T.; Bathe, K.J. A finite element formulation for nonlinear incompressible elastic and inelastic analysis. Comput. Struct. 1987, 26, 357-409. [CrossRef]

27. Reddy, M.V.; Reddy, M.C.; Reddy, P.V.; Vinod, S.R. Numerical analysis of rubber assisted sheet hydro-forming process and its experimental verification. Int. J. Mech. Prod. Eng. Res. Dev. 2018, 8, 591-600.

28. Ebrahimi, S.; Vahdatazad, N. Multi-objective optimization and sensitivity analysis of honeycomb sandwich cylindrical columns under axial crushing loads. Thin Wall Struct. 2015, 88, 90-104. [CrossRef] 